\title{
Editorial
}

\section{La verdad os hará libres}

"Se harán las investigaciones exhaustivas"... Este era el estribillo gubemamental luego de los repelidos actos delincuenciales contra personas o grupos colectivos. El estribillo perdió loda credibilidad y la verdad se convirtió en el ser desconocido. Juridicamente, esto era una usurpación del más fundamenlal derecho civil; teológicamente, tal conducta encubria una siluación de pecado estructural. Por ambas razones la cúpula del poder tendria que reaccionar lan furiosamente ante el inlorme de la Comisión de la Verdad.

Este informe dijo la primera verdad, que es la más antiguo y la raíz de las demás verdades. En su tercera parte, "cronologia de la violencia", el informe nos recuerda que la violencia y la impunidad hacen la historia del pais. El mandalo recibido por la Comisión es hacer arqueologia histórica desde las vivencias y relalos del pueblo verdadero. El informe descubre que las esferas superiores del poder opacan, intertieren o cierran los canales por donde fluye la verdad, lo cual deja más al descubierto la misma historia. La melodología es garantia de verdad: pruebas abrumadoras, pruebas sustanciales, pruebas suficientes. "La comisión decidió no llegar a ninguna conclusión especíticaen aquellos casos o situaciones o sobre cualquier aspeclo de los mismos, donde no se contaba con pruebas menos que "suficientes" en poyo de tal conclusión". (ECA; 1993. No. 533; p. 174).

Los treinla casos analizados son un muestreo representativo de una historia más larga. Irónicamenle, quienes en la misma década habían promelido hacer investigaciones exhaustivas, caso por caso, sin que nunca se obtuvieran resultados verídicos, son los que se alreven a 
desprestigiar el informe como parcial, sesgado y antiético. Se le ha puesto la capucha de intromisión nacional cuando la hisloria que relata es lo más nacional que existe. Se ha llegado a decir que es "eslúpida" la misma constitución de la Comisión de la Verdad. Tal vez esla afirmación sea una intromisión nacional en el seno de las Naciones Unidas. Si la verdad fuera tan estúpida no serían tan públicas las reacciones. Analicemos la estupidez escuchando a los acusadores.

Magistrados de Cámara, jueces de primera inslancia, jueces de paz y luncionarios del organo judicial, respaldando a la Corle Suprema, declaran categóricamente que "La Comisión se encuentra fuera del derecho salvadorefio..., que El Salvador tiene su propio derecho conslilucional, el cual crea y estructura el funcionamiento del órgano judicial, único a quien la Conslitución le faculta para juzgar y hacer ejecutar lo juzgado; lo cual signitica que dicha Comisión de la Verdad no es parte integrante del órgano judicial" (El Diario de Hoy; 20-03-93; p. 48). En resumen, que la Comisión de la Verdad se ha arrogado una función que no le compete.

La primera pregunta es si lodos eslos jueces y magistrados, que desenfundaron su lirma, habian leído detenidamente esta parte del informe, porque la Comisión de la Verdad simplemente recomienda que el Organo Judicial haga lo que por encargo constitucional debe hacer: juzgar y hacer ejecutar lo juzgado. He aqui literalmente la Introducción: "Como parte de su encargo, a la Comisión de la Verdad le corresponde lormular recomendaciones. En electo, en los términos del mandalo, el encargo de la Comisión comprende el de recomendar las disposiciones de orden legal, político o administrativo que puedan colegirse de los resullados de la investigación" (Ibidem; p. 311).

A partir de los acuerdos firmados en Chapultepec (16-01-92) se define el mandato y las funciones específicas de la Comisión de la Verdad. "La Comisión tendrá a su cargo la investigación de graves hechos de violencia ocurridos desde 1980, cuya huella sobre la sociedad reclaman con mayor urgencia el conocimiento público de la verdad... Además de las lacultades que los acuerdos de paz confieren a la Comisión con respecto a la impunidad y la invesligación de graves hechos de violencia, éstos también encargan a la Comisión elaborar recomendaciones de orden legal, politico o administrativo... De esta forma se dotó a la Comisión con dos facullades especilicas: la de realizar investigaciones y la de presentar recomendaciones. Esta última reviste singular importancia, ya que en el mandato "las partes se comprometen a cumplir con las recomendaciones de la Comisión". De esta manera las partes aceplan la obligación de_acalar_las recomendaciones de la Comisión". (Ibidem; pp. 169-170).

Este mandato y estas funciones se enmarcan en un conjunto de conve- 
nios del Derecho Inlernacional y del Derecho Humanitario de los derechos humanos que se citan en el informe y que El Salvador habia tirmado ya anles de 1980. (Ibidem; p. 172). Por no haber dedicado un tiempo prudenle a la lectura del informe y por haber olvidado lo que sin duda oyeron en la universidad, nuestros jurislas firmantes más bien han demostrado una precipitada ignorancia. La razón también puede ser otra: la última frase del pronunciamiento de estos jueces y magistrados dice algo muy cierto:... "lo cual significa que dicha Comisión de la Verdad no es parte integral del Organo Judicial". Esto es muy cierto, porque to que la Comisión de la Verdad realizó en seis meses nunca el Organo Judicial lo logro en doce anos. Llamar "estupidez" a todo este proceso es autocalificarse del mismo mal. Incluso el informe les da pie para que confesaran que habian delinquido por coacción...

Uno de los grupos prepolentes que no sólo se resiste a pedir perdón, sino que justifica su triste historial en nombre de Dios y de la Constilución es la jerarquía militar. De cara a la historia pasada, hubiera sido conveniente que la actual cúpula mililar recordara o leyera la Proclama de los jóvenes militares que dieron el golpe de estado en oclubre de 1979. Ese grupo de oficiales sintelizaba el cúmulo de situaciones o estructuras anlipopulares, que incluso "manchan la imagen de nuestra fuerza armada", al convertirse en cómplice y actor de tales injusticias sociales. (ECA; 1979; pp. 1017-1018). La Comisión de la Verdad actualiza aquella proclama militar. "La falta de garantía de los derechos humanos en El Salvador y el hecho de que una sociedad se organice al margen de los principios del Estado de derecho determina una seria responsabilidad sobre el Estado salvadoreño mismo, más que sobre éste o aquel gobierno... Con el correr del tiempo el estamento militar, más parlicularmente ciertos elementos dentro de la Fuerza Armada, al adentrarse en una dinámica de la cual difícilmente podían marginarse, terminaron por dominar por completo a las autoridades civiles, a menudo en confabulación con algunos civiles influyentes" (Ibidem; p. 311).

Al llegar a este punlo se entrelazan las pruebas abrumadoras, sustanciales y suficientes, más los hilos escondidos que nos llevan a los "civiles influyentes" acompañados enseguida con los escuadrones de la muerle, a su vez punto pendiente de investigación, a juicjo y recomendación de la Comisión de la Verdad. Esle mundillo tenebroso parece haber impactado a la actual administración de los Eslados Unidos, que ha prometido organizar su omisión ad-hoc. La voz-populi o el secreto a voces lo devela así el informe. "Ninguna de las tres ramas del poder público, judicial, legislativa o ejeculivo, fue capaz de controlar el desbordante dominio militar en la sociedad Se debilitó el sistema judicial en la medida en que la intimidación lo apresó y se sentaron las bases para su corrupción; como esle poder 
nunca habia gozado de una verdadera independencia instilucional de las ramas legislativas y ejeculiva, su ineficiencia no hizo sino incrementarse hasla convertirse, por su inanición o actilud de lamentable supedilación, en factor coadyuvante de la tragedia que ha sulrido este país. Las distintas alianzas, a menudo oportunistas, que forjaron los lideres políticos (legisladores al igual que miembros del poder ejecutivo) con el estamento militar y los miembros del poder judicial, tuvieron el efeclo de debililar aun más el conirol civil sobre las fuerzas militares, policiales y de seguridad, todas ellas parte del estamento militar" (Ibidem; pp. 311-312)

Al releer eslos párralos se comprende la necesidad, también la dificultad, del proceso de desmilitarización y reeducación del estamento mililar; pero esle embrollo de las impunidad es tan complejo que cuesla dar con el epicentro: "quién militarizó a los militares?" La amplia red de grupos ilegales armados que actuaban indiferenlemente dentro y fuera de la institucionalidad, con absoluta impunidad, conocidos como escuadrones de la muerte, sembraron el terror en la sociedad salvadorefia. Su origen lue básicamente una acción de civiles, concebida, linanciada y dirigida por ellos. El papel de los núcleos de oficiales de alla, que inicialmente se limitaba a servir de meros ejeculanles 0 ejeculores, se fue apoderando gradual y progresivamente de los escuadrones de la muerle, para un lucro personal o para promover determinados objetivos ideológicos o polílicos. Así, dentro del eslamento militar y al margen de su verdadero propósito y vocación incluso, la impunidad anle las autoridades civiles marcó la pauta. La inslitución, en su conjunto, fue presa de ciertos y determinados grupos de oficiales, que llegaron hasta a consolidarse en tandas y abusaron de su poder, de sus relaciones con ciertos elemento civiles e intimidaron a compafieros de armas renuentes a compartir o a colaborar con sus prácticas corruplas e ilícitas" (Ibidem; p. 312).

Este párrato dice muchas cosas en líneas y entre líneas. Nos dice, al igual que la Proclama militar de 1979, que también hay un delerminado grupo de militares avergonzados y doloridos por la corrupción inmanenle dentro de su luerza armada. Nos dice, sin decirlo, que contaron con suficiente información sobre la evolución y la ubicación de estos hacedores de la muerte: nos dice que no sólo son civiles, sino también olros militares, quienes desean una depuración dentro de la fuerza armada. No se harian tan repetidas reterencias a los "civiles influyentes" sino se contara con la información suficiente. El lector podrá deducirlo prosiguiendo la lectura en las páginas indicadas.

La reacción emotiva al estallido de la verdad se viste de un ropaje nacionalista. En los pasados ańos se acusaba de antipatriolas a cuantos manchaban la imagen de El Salvador con hechos "imaginarios" y propios 
de los perturbadores del orden establecido. Si los "imaginarios" eran extranjeros se les solicitaba que fueran mejor a investigar quién mató al presidenle Kennedy. Pero la Comisión de la Verdad planlea algunas preguntas muy poco imaginarias y que deben responder quienes la han tachado de parcial o unilateral; ni las preguntas ni las respuestas son unilaterales. "¿Cómo de otra manera se alcanza a entender el modus operandi de los escuadrones de la muerte? ¿La desaparición de gran canlidad de personas, los atentados contra importantes funcionarios gubernamentales, jefes de Iglesia y jueces, $y$ el hecho de que los responsables de estas atrocidades rara vez fueran llevados a juicio? Lo irónico es que este entramado de comupción, timidez y debilidad del poder judicial y de sus organos de investigación dilicultaran mucho la labor electiva del sislema judicial, incluso cuando se traló de crímenes que se atribuian al FMLN"... (lbidem. p. 312). Entre líneas parece decirse que también algunos jueces contesaron su estado de coacción...

No vamos a repetir que los inculpados, con o sin uniforme, han recurrido a la triquinuela de "inlromisión nacional", lo cual etimológicamente es muy cierto, porque la Comisión de la Verdad penetró en algo muy nacional. Como lo dijo la UNOC: "el inlorme es un juicio político y moral (no juridico; como algunos detractores prelenden hacerlo) contra los culpables de hechos deprorables contra personas; aunque debe entenderse, a la luz de sus recomendaciones, que quien está en cuestionamiento es el funcionamiento de la institucionalidad". (El Diario Latino; 20-03-93; p. 12). La UNOC loca aquí un aporte crucial del informe y de la verdad, la instilucionalidad.

En anos anteriores, ante la imposibilidad de esconder la autoria de ciertos crimenes, se nos respondia que tales hechos delictivos eran responsabilidad de delerminadas personas, desleales a sus deberes, pero que lales hechos no manchaban la instilución. La Comisión de la Verdad planta con gran clarividencia juridica y ética el problema de la doble responsabilidad. Esle es un texto muy valioso para sentar principios.

"Un aserto universalmenle mantenido establece que el sujelo de loda situación delincuencial es el ser humano, único capaz de voliciones y por 10 tanto de decisiones de voluntad; delinquen los individuos y no las instituciones creadas por ellos... Sin embargo, en ciertos contextos se presentan hechos repelitivos en el tiempo y en el espacio que parecerian rectificar la premisa anterior. Pueden darse, en efecto, reiteraciones delincuenciales en las que actúen como protagonistas dentro de la misma instilución, con analogla inequivoca, individualidades diferentes, más allá del signo político de los gobiernos y de quienes loman las decisiones; lo cual da campo para pensar que las instituciones si. delinquen, dados los mismos compor- 
tamienlos a manera de conslanle. Con mayor razón, si a la claridad de las impulaciones se sigue el encubrimienlo por parte de la institución frente a las responsabilidades que se desprenden de las investigaciones. En tales circunstancias es fácil sucumbir a la fuerza de las reiteraciones para senalar la culpabilidad instilucional". (Ibidem; p; 164) Si los repelidos actos personales generan determinadas estnucturas de comportamiemto, son estas estructuras, hechas instituciones, las que modelan y refuerzan la conducta humana.

Esie párralo de la Comisión de la Verdad Irae al recuerdo, y a la vez se refuerza con el calificalivo que el Papa Juan Pablo II utiliza para describir el orden mundial, en su encíclica La preocupación social de la Iglesia (1987). El habla de estrucluras de pecado, inlegrando la interacción de personas e instiluciones. "La suma de laclores negativos que actúan contrariamente a una verdadera conciencia del bien común universal y de la exigencia de favorecerla, parece crear en las personas y en las instituciones un obstáculo difícil de superar. Si la siluación actual hay que atribuirla a dificultades de diversa indole, se debe hablar de "estructuras de pecado", las cuales se fundan en el pecado personal y, por consiguiente, están unidas siempre a aclos concrelos de las personas que las introducen $y$ hacen dilicil su eliminación. $Y$ asi, estas mismas estructuras, se refuerzan, se difunden y son fuente de otros pecados, condicionando la conducta de los hombres... Dos parecen ser las más caracteristicas: el afán de ganancia exclusiva por una parte, y por la otra la sed de poder, con el propósito de imponer a los demás la propia voluntad..., a cualquier precio". (No. 3637).

Más cerca de nosotros Mons. Romero fustigaba la lriple estruclura de la riqueza, del poder y la estructura de la organización. Desde una lectura leologica puede resumirse el informe y nuestra historia utilizando el lenguaje del decálogo: se comienza por quebrantar el séptimo mandamiento: "no robarás"; para mantener la injusticia hay que irrespetar el quinto mandamiento:" no matarás"; para ocultar tal violencia se transgrede el octavo mandamiento: "no menlirás"; y para justificar la impunidad se le da vuella al segundo mandamiento: "no usarás el nombre de Dios en vano". EI informe de la Comisión de la Verdad ha hecho historia de este quebranlamienlo del decálogo, dando nombres concrelos a los pecados concrelos y sefialando instituciones concretas que gestan y dejan impune el pecado nacional. Para el pueblo salvadorefio se ha dicho la verdad que puede hacerle libre.

Al momento de descorrerse el telón del informe de la Comisión de la Verdad para que el público nacional contemplara el drama de su conlenido la Asamblea Legislaliva, por mayoria simple, es decir, por el volo apresu- 
rado de los represertantes de los "civiles influyentes" y de los otros poderes aquí mencionados, decrelaron una Amnistla - a priori- a tavor de los presuntos implicados en toda la cronologia de la violencia. Esta ley de amnistia ha sido al mismo tiempo una bofelada y un reconocimiento de la Verdad. Se podrá amnistiar jurídicamente a los implicados, pero en última instancia la amnistia los reconoce como culpables y esa es una gran senlencia legislaliva. Una vez más al informe ha dicho la verdad, una verdad que puede hacernos más libres y más humanos. 